\title{
Prevalence of anaemia and associated factors in pregnant women admitted in a tertiary care health institute of Jaipur, Rajasthan
}

\author{
SM Mathur ${ }^{1}$, Brajesh Kumar ${ }^{2 *}$, Amol Gite ${ }^{3}$, Rekha Mathur ${ }^{4}$, Ranjit K Jha ${ }^{5}$ \\ ${ }^{1,2}$ Associate Professor, ${ }^{3}$ Statician, ${ }^{4}$ Retired Senior Medical Officer, ${ }^{5}$ Professor and Head, ${ }^{1-3,5}$ Dept. of Community Medicine, ${ }^{4}$ Dept. of \\ Medical Health and Family Welfare, ${ }^{\mathbf{1 , 3}, 5} \mathrm{JNU}$ Institute for Medical Sciences \& Research Centre, Jaipur, Rajasthan, ${ }^{2}$ National Institute of \\ Medical Sciences \& Research Centre, Jaipur, Rajasthan, ${ }^{4}$ Government of Rajasthan, Jaipur, Rajasthan, India
}

\section{*Corresponding Author: Brajesh Kumar}

Email: brajeshchahar201@gmail.com

\begin{abstract}
Introduction: Anaemia is a global health related major public health problem among pregnant women, specially affecting developing countries like India. In pregnant women it is a major contributing factor of maternal mortality and perinatal mortality.

Objectives: 1. To find out prevalence of Anaemia in pregnant women of Jaipur. 2. To find out prevalence of Low Birth Weight newborns, Still births and Cesarian Section. 3. To find out various socio-demographic factors and their association with anaemia of pregnancy.

Materials and Methods: All pregnant women, who were admitted for delivery in Jaipur National University, Institute for Medical Sciences and Research Centre, Jaipur, Rajasthan during the study period of $1^{\text {st }}$ January 2018 to 31 December 2018.

Sampling Method and Sample Size: Study sample was calculated by complete enumeration technique and, 1227 admitted cases of delivery were selected for study.

Results: Total $64.72 \%$ of pregnant women were suffering from anaemia. Mild anaemia was $29.50 \%$, Moderate anaemia in $34.55 \%$, and Severe anaemia was observed in $0.65 \%$ of pregnant women. Total $67.67 \%$ Hindu pregnant women were anaemic while only $60.40 \%$ Muslim pregnant women were found to be anaemic. Among the anaemic mothers, $21.92 \%$ had newborn birth weight less than $2 \mathrm{~kg}$, $24.05 \%$ had birth weight $2-2.5 \mathrm{~kg}$ and $54.03 \%$ had birth weight more than $2.5 \mathrm{~kg}$ weight. $50.88 \%$ delivered normally and $47.60 \%$ underwent LSCS. $1.52 \%$ had stillbirth among anaemic pregnant women.

Conclusion: Improved dietary practices, consumption of locally available iron rich foods and a balanced diet, and effective national programme will go a long way in preventing iron deficiency in pregnant women.
\end{abstract}

Keywords: Anaemia, LSCS, Still birth, Pregnant women.

\section{Introduction}

Anaemia is a global health related major public health problem among pregnant women in all countries, specially affecting more in developing countries like India. Anaemia occurs at all stages of life but more prevalent in pregnant women and young children. High prevalence of anaemia in country indirectly affects its social and economical development, as it is responsible for reduced work capacity and high sickness. In case of pregnant women it is a major contributing factor of high maternal mortality and perinatal mortality. WHO (2008) estimates that about half (48.8\%) of the entire world population suffer from anaemia. More than three-fourth of all pre-school children, one-third of all children of school going age, $70 \%$ of women have anaemia and more than $40 \%$ men suffer from anemia. ${ }^{1}$ As per anaemia policy brief (WHO 2014), in 2011, 29\% (496 million) of non pregnant women and $38 \%$ (32.4 million) of pregnant women aged 15-49 years were anaemic. ${ }^{2}$ South Asia and parts of Central and West Africa reported highest prevalence of anemia. $^{3}$ The populations of developed countries are not by any means completely free from anaemia, and a significant percentage of women of childbearing age (estimated between 4 and 12 percent )suffer from anemia. ${ }^{4} \mathrm{WHO}(1968)$ Techn. Rep. Ser. No.405, reported the prevalence of anaemia from Morogoro municipality, Tanzania, 2010, South Eastern Nigeria, 2007, Sudan, 2009, Kenya, 2007, Uganda, 2013, China, 2009, Malaysia, 2012 and Gilgel Gibe dam area, Southwest
Ethiopia, 2012 reported 95\%, 76.9\%, 70\%, 69.1\%, 63.1\%, $58.6 \%, 57.4 \%$ and $53.9 \%$ prevalence rates, respectively. ${ }^{5}$

Unfortunately India is also classified in as a "severe" public health problem group ( $>40 \%$ prevalence in all groups, pre-school children, pregnant, and non-pregnant women). While analyzing the data for states with anaemia level of 70\% among children, it was found that, except for Punjab, all other states had more than 50\% prevalence of anaemia among pregnant women. According to NFHS4(2015-16) Pregnant women aged 15-49 years found anaemic $(\mathrm{Hb}<11.0 . \mathrm{g} / \mathrm{dl})$ in $45.7 \%$ Urban pregnant and $52.1 \%$ Rural pregnant. ${ }^{6}$ The overall prevalence of anaemia was 50.14 per cent among ante-natal women in the prevalence of anaemia among pregnant women in a community-based study in Udupi district, by Judith A. Noronha et al, which is nearly equal to the prevalence in Karnataka i.e, 54\%. ${ }^{7}$ Higher prevalence of anaemia (87.4\%) was found by Srivastava et al (2005). ${ }^{8}$ A survey by the Indian Council of Medical Research has shown, more than $50 \%$ of adolescents, children, and pregnant women are anaemic. Suryanarayana et al. conducted a study in Kolar district and showed prevalence of $63 \%$ among pregnant women. ${ }^{9}$ In a study by Siddalingappa $\mathrm{H}$ et al in rural area of Mysore, $64.2 \%$ of pregnant women were anaemic and there was a significant association between anaemia and factors such as age at first pregnancy, sociodemographic characteristics, and parity. ${ }^{10}$ About $16 \%$ of maternal mortality is because of anaemia in India. 
While the literature reviewed, only a handful studies have been conducted so far, particularly in Rajasthan that tries to identify the prevalence of anaemia in pregnant women and associated factors affecting it. So this study was conducted in a tertiary level healthcare institute, JNU IMSRC, Jaipur, with the following aims and objectives.

\section{Aims and Objectives}

1. To find out prevalence of Anaemia in pregnant women admitted in a tertiary level healthcare institute of Jaipur.

2. To find out prevalence of Low Birth Weight newborn, Still births and occurrence of Cesarian Section among the anaemic pregnant women.

3. To find out various socio-demographic factors and its association with anaemia in pregnant women.

\section{Materials and Methods}

\section{Study type}

A hospital based cross sectional observational study.

\section{Study population and area}

All pregnant women, who were admitted for delivery in Jaipur National University, Institute for Medical Sciences and Research Centre (JNUIMSRC), Jaipur, Rajasthan during the study period of $1^{\text {st }}$ January 2018 to 31 December 2018.

\section{Sampling method and sample size}

Complete enumeration technique was used and total of 1227 admitted cases of delivery were selected for study purpose.

\section{Inclusion and exclusion criteria}

All consenting pregnant women who were admitted for delivery in JNU-IMSRC, Jaipur were included in this study. Pregnant women who did not gave consent, or left against medical advice (LAMA) or referred were not included in this study.

\section{Statistical analysis}

Data analysis was done by SPSS 22.0 version. Descriptive statistics expressed in frequency and percentages. Chi square statistics applied to assess the association between different variables. $\mathrm{P}$ value $<0.05$ was taken as significant.

\section{Observations}

Table 1: Distribution of respondents according to severity of anaemia as per ICMR criteria of anaemia

\begin{tabular}{|c|c|c|c|}
\hline \multirow{2}{*}{\multicolumn{2}{|c|}{ Category }} & \multicolumn{2}{|c|}{ Anaemia severity } \\
\hline & & No. of cases & Percentage \\
\hline Normal & $\geq 11 \mathrm{~g} / \mathrm{dl}$ & 433 & 35.29 \\
\hline Mild & $10-10.9 \mathrm{~g} / \mathrm{dl}$ & 362 & 29.50 \\
\hline Moderate & $7.0--9.9 \mathrm{~g} / \mathrm{dl}$ & 424 & 34.56 \\
\hline Severe & $4-6.9 \mathrm{~g} / \mathrm{dl}$ & 8 & 0.65 \\
\hline Very Severe & $<4 \mathrm{~g} / \mathrm{dl}$ & 0 & 0.00 \\
\hline Total & & 1227 & $100 \%$ \\
\hline
\end{tabular}

Table 2: Distribution of respondents according to religion as per ICMR criteria of anaemia

\begin{tabular}{|l|c|c|c|}
\hline Category & & Hindu & Muslim \\
\hline Normal & $>11 \mathrm{~g} / \mathrm{dl}$ & $237(32.33 \%)$ & $196(39.60 \%)$ \\
\hline Mild & $10-10.9 \mathrm{~g} / \mathrm{dl}$ & $221(30.15 \%)$ & $141(28.54 \%)$ \\
\hline Moderate & $7.0-9.9 \mathrm{~g} / \mathrm{dl}$ & $271(36.92 \%)$ & $153(30.91 \%)$ \\
\hline Severe & $4-6.9 \mathrm{~g} / \mathrm{dl}$ & $4(0.55 \%)$ & $4(0.81 \%)$ \\
\hline Very Severe & $<4 \mathrm{~g} / \mathrm{dl}$ & 0 & 0 \\
\hline Total & $1227(100 \%)$ & $733(59.73 \%)$ & $494(40.26 \%)$ \\
\hline
\end{tabular}

Chi - square calculated is significant, with $\mathrm{p}$ - value 0.0429 at $5 \%$ level of significance.

It means, Religion of respondents is related with severity of anaemia.

Table 3: Distribution of respondents according to age group as per ICMR Criteria of anaemia

\begin{tabular}{|c|c|c|c|c|c|}
\hline \multicolumn{2}{|l|}{ Category } & $<20 \mathrm{yrs}$ & 20-24 yrs & $>24 \mathrm{yrs}$ & Total \\
\hline Normal & $>11 \mathrm{~g} / \mathrm{dl}$ & $17(21.3 \%)$ & $398(35.7 \%)$ & $18(58.1 \%)$ & $433(35.28 \%)$ \\
\hline Mild & $10-10.9 \mathrm{~g} / \mathrm{dl}$ & $12(15 \%)$ & $347(31.1 \%)$ & $3(9.7 \%)$ & $362(29.50 \%)$ \\
\hline Moderate & $7.0-9.9 \mathrm{~g} / \mathrm{dl}$ & $50(62.5 \%)$ & $364(32.6 \%)$ & $10(32.3)$ & $424(34.55 \%)$ \\
\hline Severe & $4-6.9 \mathrm{~g} / \mathrm{dl}$ & $1(1.3 \%)$ & $7(0.6 \%)$ & 0 & $8(0.65 \%)$ \\
\hline Very Severe & $<4 \mathrm{~g} / \mathrm{dl}$ & 0 & 0 & 0 & 0 \\
\hline Total & & $80(6.51 \%)$ & $1116(90.95 \%)$ & $31(2.52 \%)$ & 1227 \\
\hline
\end{tabular}

Chi - square calculated is highly significant, with $\mathrm{p}$ - value 0.0001 at $5 \%$ level of significance.

It means, Age of respondents is related to severity of anaemia. 
Table 4: Distribution of respondents according to birth weight, as per ICMR Criteria of anaemia

\begin{tabular}{|l|c|c|c|c|c|}
\hline Category & \multicolumn{1}{|c|}{} & $\mathbf{2 . 0} \mathbf{~ k g}$ & $\mathbf{2 . 0 - 2 . 5} \mathbf{~ k g}$ & $>\mathbf{2 . 5} \mathbf{~ k g}$ & Total \\
\hline Normal & $>11 \mathrm{~g} / \mathrm{dl}$ & $\mathbf{5 8}(\mathbf{2 5 \%})$ & $85(30.80 \%)$ & $290(40.33 \%)$ & 433 \\
\hline Mild & $10-10.9 \mathrm{~g} / \mathrm{dl}$ & $84(36.21 \%)$ & $98(35.51 \%)$ & $180(25.03 \%)$ & 362 \\
\hline Moderate & $7.0-9.9 \mathrm{~g} / \mathrm{dl}$ & $89(38.36 \%)$ & $92(33.33 \%)$ & $243(34.79 \%)$ & 424 \\
\hline Severe & $4-6.9 \mathrm{~g} / \mathrm{dl}$ & $1(0.43 \%)$ & $1(0.36 \%)$ & $6(0.83 \%)$ & 8 \\
\hline Very Severe & $<4 \mathrm{~g} / \mathrm{dl}$ & 0 & 0 & 0 & 0 \\
\hline \multicolumn{2}{|l|}{ Total } & $232(18.90 \%)$ & $276(22.49 \%)$ & $719(58.59 \%)$ & 1227 \\
\hline
\end{tabular}

$\mathrm{Chi}$ - square calculated is highly significant, with $\mathrm{p}$ - value 0.000112 at $5 \%$ level of significance. It means, Weight of new born baby is related to severity of anaemia.

Table 5: Distribution of respondents according to pregnancy outcome as per ICMR Criteria of anaemia

\begin{tabular}{|l|c|c|c|c|c|}
\hline Category & & Normal & LSCS & Still birth & Total \\
\hline Normal & $>11 \mathrm{~g} / \mathrm{dl}$ & $322(74.36 \%)$ & $103(23.78 \%)$ & $8(1.85 \%)$ & 433 \\
\hline Mild & $10-10.9 \mathrm{~g} / \mathrm{dl}$ & $204(50.28 \%)$ & $155(48.9 \%)$ & $3(0.83 \%)$ & 362 \\
\hline Moderate & $7.0-9.9 \mathrm{~g} / \mathrm{dl}$ & $198(46.7 \%)$ & $217(51.18 \%)$ & $9(2.13 \%)$ & 424 \\
\hline Severe & $4-6.9 \mathrm{~g} / \mathrm{dl}$ & 2 & 6 & 0 & 8 \\
\hline Very Severe & $<4 \mathrm{~g} / \mathrm{dl}$ & 0 & 0 & 0 & 0 \\
\hline \multicolumn{2}{|l|}{ Total } & $726(59.16 \%)$ & $481(39.20 \%)$ & $20(1.62 \%)$ & 1227 \\
\hline
\end{tabular}

\section{Discussion}

Broadly speaking, Nutritional anaemia is a disease syndrome caused by malnutrition, as per WHO. Anaemia is defined as a condition in which haemoglobin content of blood is lower than normal may be as a result of deficiency of one or more essential nutrients, regardless of the cause of such deficiency. Anaemia is established if the haemoglobin is below the cut-off point recommended by WHO, $11 \mathrm{~g} / \mathrm{dl}$ for adult pregnant female. Main cause of nutritional anaemia is iron deficiency, and less frequently foliate or vitamin B12 deficiency.

As shown in table 1, in present study $35.28 \%$ pregnant women were found to be normal and $64.72 \%$ were suffering from anaemia of various severity. Mild anaemia was $29.50 \%$, Moderate anaemia in $34.55 \%$, and Severe anaemia was observed in $0.65 \%$ of pregnant women in present study. Judith AN, et al in their study, Prevalence of anaemia among pregnant women: a community-based study in Udupi district, observed the prevalence of mild, moderate, and severe anaemia as $27 \%, 34 \%$, and $3 \%$, respectively. Higher prevalence of anaemia $(87.4 \%)$ was found by Shrivastva et al which is comparable with the studies conducted by Sharma et al. in Rajasthan and by Wadgav HV. Mondal et al. reported that majority of the anaemic women belonged to moderate anaemia (91.46\%). Similarly, Kumar et al. observed a very low prevalence of severe anaemia $(0.6 \%)$. A study in Andhra Pradesh by Vemulapalli and Rao and that by Ahmed et al. observed higher rates of severe anaemia: $6.28 \%$ and $18.9 \%$, respectively. Detels $\mathrm{R}$, et al, United States, revealed in their study anaemia prevalence during pregnancy differing from $18 \%$ in developed countries to $75 \%$ in South Asia. Taner et al reported prevalence of $41.6 \%$. A survey by the Indian Council of Medical Research has shown, more than $50 \%$ of adolescents, children, and pregnant women are anaemic. Suryanarayana et al. conducted a study in Kolar district and showed prevalence of $63 \%$ among pregnant women. In a study by
Siddalingappa $\mathrm{H}$ et al in rural area of Mysore, $64.2 \%$ of pregnant women were anaemic

As shown in table 2, in present study, only $67.67 \%$ Hindu pregnant women were anaemic while $60.40 \%$ Muslim pregnant women were found to be anaemic. This difference might be due to their non-vegetarian dietary habits. In a study by Leyla Karaoglu et al, The prevalence of nutritional anaemia in an east Anatolion province, Turkey, they found anaemia was majorly seen in vegetarian ( $37.0 \%){ }^{11}$ Rajamouli $\mathrm{J}$ et al, also in their Study on Prevalence of Anaemia among Pregnant Women attending Antenatal Clinic at Rural Health Training Centre (RHTC) and Chalmeda Anand Rao Institute of Medical Sciences Teaching Hospital, Karimnagar, Telangana, observed that the vegetarian group of pregnant women were maximum $(40.14 \%)$ with anaemia as compared with having mixed dietary habits $(18.21 \%){ }^{12}$. In similar type of study by Baig Ansary. N, Badruddin SH it was stated in the literature that tea consumption and low intake of red meat were associated with anemia. ${ }^{13}$ Meat is a good source of high quality protein, iron, zinc and all vitamins.

As shown in table $3,7.93 \%$ of anaemic pregnant women were of $<20$ yrs age group, 90.42\% were from 20-24 years age group and $1.62 \%$ from $>25$ years age group in present study, this shows that anaemia is more common in young girls. In Leyla $\mathrm{K}$ study it was seen that the mean ages of anaemic and non-anaemic pregnant women were similar. 26.9 and 26.4years respectively $(p>0.05)$. Ahmad $\mathrm{Z}$ et al in their study stated that the age of the mother is significantly associated with anaemia, with the majority of mothers $(56.6 \%)$ who are more than 40 years old being anaemic at the first antenatal visit. Getachew M, et al in their study, Anaemia and associated risk factors among pregnant women in Gilgel Gibe dam area, Southwest Ethiopia observed that the majority $(73 \%)$ of the anaemic pregnant women were in age group of 20-24 years. Kaul et al. in Kashmir valley observed a very high prevalence $(93.67 \%)$ of anaemia in the 
similar age group, and in the study by Sharma et al. in Rajasthan city, only $38 \%$ of women were anaemic in the similar age group. Judith et al. in Udupi showed the prevalence of anaemia to be $57.72 \%$ among antenatal women who were in the age group of 17-21 years. During childhood, the low dietary intake of iron and poor bioavailability of iron result in high prevalence of anaemia. Anaemia gets aggravated with increased in requirements during adolescence and pregnancy. Early marriage and early adolescent pregnancy aggravates anaemia, contributing to high prevalence in this age group.

As shown in table 4, among the normal pregnant women group $13.39 \%$ had newborn weight less than $2 \mathrm{~kg}$. $19.63 \%$ had weight 2 to $2.5 \mathrm{~kg}$ and $66.97 \%$ had normal weight more than $2.5 \mathrm{~kg}$ in present study. On other hand among the anaemic mothers $75 \%$ had birth weight less than $2 \mathrm{~kg}, 69.40 \%$ had birth weight $2-2.5 \mathrm{~kg}$ and $59.67 \%$ had birth weight more than $2.5 \mathrm{~kg}$ weight. Shoboo Rahmati B.Sc.et al, in Maternal Anaemia during pregnancy and infant low birth weight; A systematic review and Metaanalysis revealed, Overall, 17 studies with a total sample size of 245407 entered the final meta-analysis and demonstrated that the relative risk for maternal anaemia in the first, second and third trimester of pregnancy were 1.26 (95\% CI: $1.03-1.55), 0.97$ (95\% CI: $0.57-1.65$ ), and 1.21 (95\% CI: 0.84-1.76), respectively. The relationship between maternal anaemia and infant low birth weight in the first trimester of pregnancy was significant. ${ }^{14}$ In Manisha Chouhan et al study the risk of low birth weight is more in anaemic group and it increases with severity of anaemia. In mild- moderate anaemic group about $55 \%$ of new born baby have birth weight $2-2.5 \mathrm{~kg}$. and in severely anaemic group $52 \%$ of new born baby have birth weight $<2 \mathrm{~kg}$. It revealed $7 \%$ in non-anaemic group and $52 \%$ in severely anaemic group; that is 7 times more than non-anaemic group. ${ }^{15}$

As shown in table 5, in present study among the normal women $74.36 \%$ delivered normally, $23.79 \%$ had to go LSCS and only $1.85 \%$ had still births. On other hand among the anaemic pregnant women $50.88 \%$ delivered normally and $47.60 \%$ underwent LSCS. Still birth was observed in $1.51 \%$ of anaemic pregnant women. It looks as if increased LSCS and timely intervention in anaemic mother could help in reducing still birth among them. It was also observed that still birth was most commonly observed (45\%)in moderately anaemic pregnant women, similarly LSCS was most commonly observed $(45.68 \%)$ in moderately anaemic pregnant women showing that occurrence of these events is influenced by anaemia of mother.

Newborn of mothers are not only likely to be anaemic but also have lower body iron reserve. The more severe the maternal anaemia, more adverse is the consequence for the child. There is usually a 2-3 fold increase in perinatal mortality rate when maternal $\mathrm{Hb}$ level falls below $8 \mathrm{~g} / \mathrm{dl}$, and this escalates to 8-10 fold increase when the maternal $\mathrm{Hb}$ level is $<5.0 \mathrm{~g} / \mathrm{dl}$. Pratiksha Gupta et al, observed in their study, Is vaginal delivery safe after previous lower segment caesarean section in developing country? Women, with one previous lower segment caesarean section (LSCS), live pregnancy with haemoglobin $\geq 8 \mathrm{~g} / \mathrm{dl}$. were included in this study. Incidence of CS in study period of 2 years was $12.14 \%$, previous CS was $3.33 \%$ and repeats CS was $19.5 \% .{ }^{16}$ Incidence of LSCS in normal pregnant women was higher in present study, could be explained due to their multiparty, low socio-economic profile and late admission to hospital by pregnant women. As per' Pregnancy Labor and Birth' Office on women Health, U.S. Department of Health and Human Services, in the United States about 33\% of deliveries are by $\mathrm{C}$-section. The rates in the UK and Australia are $26.5 \%$ and $32.3 \%$ respectively. In China, the most recent CS rate reported was $41 \%$.Globally, $1 \%$ of all caesarean deliveries are carried out without medical need. Overall, the caesarean section rate was $25.7 \%$ for 20042008. Global rates of caesarean section rates are increasing. It doubled from 2003 to 2018 to reach $21 \%$, and is increasing annually by $4 \%$. In southern Africa it is less than $5 \%$; the rate is almost $60 \%$ in some parts of Latin America. In the United Kingdom, in 2008, the rate was 24\%. ${ }^{17}$ Manisha Nair et al, Working at: National Perinatal Epidemiology Unit (NPEU), Nuffield Department of Population Health, University of Oxford; the Royal Wolverhampton NHS Trust and Guy's and St Thomas' NHS Foundation Trust in their study Association between maternal haemoglobin and stillbirth: a cohort study among a multi-ethnic population in England found In singleton babies born at or after $24^{+0}$ weeks of gestation, the crude odds of stillbirth decreased by $25 \%$ per unit increase in the haemoglobin concentration at first visit $[\mathrm{OR}=0.75,95 \%$ confidence interval (CI) 0.62-0.92, $\mathrm{P}=0 \cdot 004]$. After adjusting for 11 other risk factors, the odds of stillbirth decreased by $30 \%$ per unit increase in the haemoglobin concentration (i.e. per $10 \mathrm{~g} / \mathrm{l}$ increase in haemoglobin concentration) [adjusted odds ratio $(\mathrm{aOR})=0.70,95 \% \mathrm{CI}$ $0 \cdot 58-0 \cdot 85, \mathrm{P}=0 \cdot 001]$. The association between maternal haemoglobin concentration at 28 weeks and stillbirth was not statistically significant at $\mathrm{P}<0.05$, but an inverse linear association was observed $(\mathrm{OR}=0.86,95 \%$ CI 0.65 $1 \cdot 14, \mathrm{P}=0.277) ; \quad \mathrm{aOR}=0.83, \quad 95 \% \quad$ CI $\quad 0.63$ $1 \cdot 11, \mathrm{P}=0 \cdot 207) .{ }^{18}$ Maternal anaemia is very prevalent among pregnant women of our setting. It strongly contributes to worsening of morbidities that act with pregnancy high-risk factors in raising the risk of caesarean section, prematurity, SGA and stillbirth.

\section{Conclusion}

Looking to above state of affairs regarding anaemia among pregnant women, India is facing a great problem which requires immediate effective intervention. As per NFHS-4, only $30.3 \%$ antenatal women had reportedly consumed Iron folic acid tablets for 100 days or more while they were pregnant. Anaemia among pregnant women is mostly due to increased requirement and decreased intake due to low socio-economic status, poor dietary practices, consumption of low iron and protein diet. Sometimes decreased absorption and utilization is also observed at times as because of overcooking of food, presence of dietary factors like tannins, phytates and divalent ions in tea, coffee, 
carbonated drinks. Fiber and milk may also result in poor absorption and utilization of iron. Women lose a considerable amount of iron especially during menstruation. Malaria and hookworm infestation also enhance the problem of anaemia in pregnant women for which GOI had launched Anti-malaria and Deworming programme. In addition mothers who have born children at close intervals become anaemic due to the additional demands of the rapid pregnancies and the loss of blood in each delivery, thereby requiring strengthening of family welfare programme.

Improved dietary practices, consumption of locally available iron rich foods and a balanced diet, will go a long way in preventing iron deficiency in pregnant women. At times our caregivers like ANM, ASHA, AWW and other peer educators are not aware of issues of iron deficiency, it requires improvement.

National Iron - plus Initiative, WIFS food fortifications etc, are the efforts made by Indian Government to tackle the problem of anaemia. Double -fortified salt (DFS) has been introduced in mid-day meal and ICDS program. Fortification of wheat flour with Iron (NaFeEDTA), folic acid, zinc, vitamin B has been tried in M.P., Gujarat, Mumbai, and Haryana to assess feasibility, cost implications and logistical issues before introducing the same in ICDS, MDM, and PDS in future.

The highest level of political commitment to control anaemia was displayed in 2018 when the Honourable Prime Minister of India launched the Anaemia Mukt Bharat (AMB) program. Under this program, an ambitious target of annual reduction in the prevalence of anaemia by $3 \%$ from the NFHS -4 level has been set by GOI, Still there is a long way to go, to tackle the problem of anaemia in pregnant women in India which requires a sincere and constant really effective scientific approach.

\section{Source of Funding}

No funding sources.

\section{Conflicts of Interest}

None declared.

\section{Ethical Approval}

The study was approved by the Institutional Ethics Committee.

\section{References}

1. Kalaivani K. Prevalence and consequences of anaemia in pregnancy. Indian J Med Res. 2009;130:627-33.

2. Global Nutrition Target 2025, Anaemia policy brief. WHO/NMH/NHD/14.4.

3. WHO, Global nutrition targets 2025; anaemia policy brief WHO, 2018 (online). Available from http;//apps. WHO. Int/iris/ bit stream/handle/10665/148556/WHO_NMH_NHD_14.4_eng.pd f? sequence $=1$.
4. Scott SP, Chen-Edinboro LP, Caulfield LE, Murray-Kolb LE. The impact of anaemia on child mortality; An updated review. Nutrients. 2014;6;5915-32.

5. WHO (1968) Techn Rep Ser No. 405. [Last accessed on 2018 Dec 20]

6. National Family Health Survey (NFHS-4) Report, India 2014-15; International Institute for Population Sciences, Mumbai, India. Available from: http://www.rchiips.org/ NFHS/pdf/NFHS4/KA_FactSheet.pdf. [Last accessed on 2018 Dec 20]

7. Judith A. Noronha JA, Bhaduri A, Bhat HV. Prevalence of anaemia among pregnant women: a community-based study in Udupi district. Health Popul Perspect Issues. 2008;31(1):3140.

8. Srivastava A, Prabha T, Quershi S. Anaemia in Pregnancy- A Novel Regime of Intramuscular Iron Therapy. J Obstet Gynaecol India. 2005;55(3):237-40.

9. Suryanarayana R, Chandrappa M, Santhuram AN. Prospective study on prevalence of anaemia of pregnant women and its outcome: A community based study. J Family Med Prim Care. 2017;6:739-43.

10. Siddalingappa H, Murthy MR, Ashok NC. Prevalence and factors associated with anaemia among pregnant women in rural Mysore, Karnataka, India. Int J Community Med Public Health. 2016;3:2532-7.

11. Karaoglu L, Pehlivan E, Egri M, Deprem C, Gunes G, Genc $\mathrm{MF}$, et al. The prevalence of nutritional anemia in an east Anatolion province, Turkey. BMC Public Health. 2010;10;329.

12. Rajamouli J, Ravindra A, SCK Reddy, Pambi S. Study on prevalence of Anaemia among pregnant women attending Antenatal clinic at RHTC and Chalmeda Anand Rao Institute of Medical Sciences Teaching Hospital, Karimnagar, Talangana, India. Int J Contamporary Med Res. 2016;3(8):2388-91.

13. Baig-Ansary N, Badruddin SH, Karmaliani R, Harris H, Jehan $\mathrm{I}$, Pasha $\mathrm{O}$, et al. Anemia prevalence and risk factors in pregnant women in a urban area of Pakistan. Food Nutr Bull. 2008;29(2):132-9.

14. Rahmati S, Delpishe A, Azami M, Hafezi Ahmadi MR, Sayehmiri K. Maternal Anemia during pregnancy and infant low birth weight; A systematic review and Metaanalysis. Int J Reprod BioMed. 2017;15(3):125-34.

15. Chouhan M, Tomar S. Anaemia in Pregnancy a Prospective Observational Study in Tertiary Care teaching hospital of North India. J Med Sci Clin Res. 2013;1(4)195-8.

16. Gupta P, Jahan I, Jograjiya GR. Is vaginal delivery safe after previous lower segment caesarean section in developing country? Niger Med J. 2014;55(3):260-5.

17. Pregnancy Labor and Birth. Office on Women's Health, U.S. Department of Health and Human Services. 1 February 2017. (Retrieved on 15 July 2018).

18. Nair M, Knight M, Robinson S, Nelson-Piercy C, Stanworth SJ, Churchill D. (2018). Pathways of association between maternal haemoglobin and still birth; path-analysis of maternity data from two hospitals in England. $B M J$ Open. 2018;8:e20149.

How to cite this article: Mathur SM, Kumar B, Gite A, Mathur R, Jha RK. Prevalence of anaemia and associated factors in pregnant women admitted in a tertiary care health institute of Jaipur, Rajasthan. Indian J Forensic Community Med. 2020;7(1):19-23. 